\title{
Caracterização das ondas de superfície na plataforma interna do Estado do Paraná, Brasil
}

\author{
Characterization of surface waves on the inner shelf of the Paraná State \\ DOUGLAS DUARTE NEMES*, EDUARDO MARONE** \\ * Universidade Federal do Paraná - Centro de Estudos do Mar, Pontal do Paraná - PR-douglasnemes@hotmail.com \\ ** Universidade Federal do Paraná - Centro de Estudos do Mar, Pontal do Paraná - PR- marone@gmail.com
}

\begin{abstract}
Resumo
Através de fundeios oceanográficos (correntômetro/ondógrafo eletromagnético S4 ADW InterOcean) nas isóbatas de $18 \mathrm{~m}$ e $30 \mathrm{~m}$ na plataforma interna rasa paranaense foram medidos durante 14 meses dados de ondas (Jul/2009 - Nov/2010), obtendo-se uma série capaz de mostrar a variabilidade intra-anual. Um número suficiente de tempestades foi identificado na série de dados para poder compreender o clima de ondas do Estado do Paraná. A predominância direcional da incidência de ondas na plataforma interna rasa paranaense foi SSE com diminuição da altura significativa de ondas dos $30 \mathrm{~m}$ aos $18 \mathrm{~m}$ de profundidade. $O$ estado de vagas predominou sobre o estado de swell durante as temporadas registradas pelo presente estudo. Os sistemas meteorológicos mais importantes para a geração de eventos extremos e dos principais estados de swell ou eventos de alta energia de ondas foram os ciclones subtropicais.
\end{abstract}

Palavras-chave: clima de ondas; pista de ventos; espectro de ondas; ciclones subtropicais.

\begin{abstract}
Two years of wave data (Jul/2009 - Nov/2010) were recorded by Interocean S4 ADW's from the inner (18m) and outer (30m) continental shelfin the Paraná State. A sufficient of data were obtained in order to characterize the wave sazonality and the record of several storms events. The main direction wave propagation on the inner shelf was SSE. Short period waves predominated over the swells with a significant loss of wave height at $18 \mathrm{~m}$ compared with the data at $30 \mathrm{~m}$. The most important weather systems for the generation of high-energy wave events was the subtropical cyclones.
\end{abstract}

Keywords: climate of waves; fetch; wave's spectrum, subtropical cyclones

\section{Introdução}

A hidrodinâmica ao longo da linha de costa é o resultado da interação da ação das ondas incidentes, que arrebentam e geram fluxos, e a variação da maré (Wrigth e Short, 1984; Calliari et al. 2003). A definição dos padrões de distribuição de energia da onda ao longo da costa contribui para a previsão de possíveis mudanças na configuração da linha de costa, evitando, ou minimizando as perdas físicas e econômicas (Silva et al. 2001). A necessidade de dados climáticos de ondas, principalmente para as praias ditas oceânicas ou abertas, é extremamente importante (Short, 1999; Klein et al. 2003) e fundamentais para operações navais, atividades marítimas comerciais e proteção costeira (Caetano Neto et al. 1996).

Na costa sul do Brasil o regime de ondas é dado pelo padrão de ventos no Atlântico Sul (Araújo et al. 2003), onde as perturbações meteorológicas em escala sinótica mais importante sobre a plataforma continental sul e sudeste do Brasil são os sistemas frontais (Reboita, 2008; Reboita et al. 2010). Os ventos de maior energia sobre a superfície do mar nesta região da costa brasileira são consequência da passagem de ciclones extratropicais (Rocha et al. 2004). Tais fenômenos representam um importante impacto econômico negativo quando presentes na região sul e sudeste do Brasil (Rocha et al. 2004; Reboita et al. 2010). Os ciclones são um complexo fenômeno atmosférico e podem variar na intensidade, duração, deslocamento, frequência e estrutura vertical (Wang et al. 2005). Estes fenômenos meteorológicos estão associados com uma estrutura atmosférica com características baroclínicas e a passagem de ciclones extratropicais no sul do Brasil é observada acompanhada de alta agitação marítima (Goya e Tessler, 2000; Rocha et al. 2004; Parise et al. 2009). 
Diversos trabalhos descrevem a dinâmica e desenvolvimento de vórtices ciclônicos entre $15^{\circ} \mathrm{S}$ e $40^{\circ} \mathrm{S}$, na região Sul e Sudeste do Brasil (Alves e Melo, 2001; Fyfe, 2003; Rodrigues et al. 2004; Reboita, 2008; Reboita et al. 2009; Reboita et al. 2010; Parise et al. 2009; Alves et al. 2009). Dependendo da trajetória dos centros de pressão atmosférica, da ciclogênese associada e dos sistemas frontais induzidos pelos mesmos, a agitação marítima pode refletir-se na costa brasileira ou não, sendo que a intensidade de tal agitação está diretamente relacionada com a referida trajetória e a proporção de tal fenômeno (lapar, 1978).

Mctaggart-Cowan et al. (2006) observaram à existência de um sistema tropical identificado no Oceano Atlântico Sul, o Furacão Catarina (2004), que se desenvolveu a partir de um ciclone subtropical, sendo assim, os autores sugerem uma revisão do convencional conhecimento pertinente na climatologia desta região.

Os trabalhos para buscar caracterizar o clima de ondas no Estado do Paraná iniciaram-se com Bandeira (1974), obtendo registros pontuais com um ondógrafo autônomo a ultrassom, fundeado a $10 \mathrm{~m}$ de profundidade na plataforma continental interna rasa, no meio do arco praial Pontal do Sul - Ponta de Matinhos. Duas outras campanhas de amostragens de ondas foram realizadas pela Portobrás (1983) a 16,5 m e INPH (1985), próximo ao arquipélago de Currais. Marone e Camargo (1994) coletaram dados de ondas entre a ilha da Galheta e o Balneário Atami para a caracterização física do Complexo Estuarino de Paranaguá. Martins (2002) realizou coletas de dados de ondas nas proximidades da zona de arrebentação no Balneário Atami. Porto Lima (2008) utilizou um correntômetro/ondógrafo S4 ADW para medir parâmetros de ondas a $10 \mathrm{~m}$ de profundidade, com o objetivo de alimentar um modelo numérico de ondas e desenvolver um método com recife artificial multifuncional para conter a erosão costeira no município de Matinhos (PR). Segundo Porto Lima (2008), a principal direção de incidência de ondas foi SE com altura máxima de ondas de 5,44 $\mathrm{m}$.

Contudo, dada à dificuldade de se instalar e manter sensores de medidas de ondas por longos períodos, a disponibilidade destes dados em escala climatológica é pequena em toda costa brasileira (Araújo, et al. 2003). No presente estudo foi caracterizado o clima de ondas na região central da plataforma interna rasa do Estado do Paraná identificando o principal fenômeno atmosférico gerador de alta energia de ondas para a região com uma série de dados de ondas de quase dois anos. Os novos dados de ondas são úteis na compreensão dos processos dinâmicos da plataforma e das praias oceânicas dos municípios paranaenses, bem como a gênese e dinâmica característica dos eventos extremos.

\section{Materiais e método}

A continuidade da linha de costa paranaense é interrompida por duas importantes baías: o Complexo Estuarino de Paranaguá e; a Baía de Guaratuba. A região oceânica central da costa paranaense (Figura 1), onde se localizam as mais importantes cidades costeiras do Paraná, está inserida dentro do arco praial Pontal do Sul (25우 34 'S e

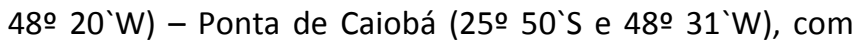
comprimento em torno de $35 \mathrm{~km}$ e orientação aproximada NE-SW.

Para caracterizar as ondas de superfície foram utilizados dois correntômetro/ondógrafos eletromagnéticos S4 ADW InterOcean fundeados um a $18 \mathrm{~m}$ (\#18) e $30 \mathrm{~m}$ (\#30) de profundidade (Figura 1). Os instrumentos foram configurados para obtenção de registros de $18 \mathrm{~min}$ com taxas amostrais de $2 \mathrm{~Hz}$, em intervalos de $4 \mathrm{~h}$ (como sugerido por Holthuijsen, 2007). Esta configuração estabelece uma autonomia do equipamento de 3 a 5 meses. O ponto \# 18 (25 $44^{\prime} \mathrm{S}$ e 48ㅇ $20^{\prime} \mathrm{W}$ ) localizou-se a 14 $\mathrm{km}$ da linha de costa e o ponto \# 30 (25은 $41^{\prime} \mathrm{S}$ e 48은 $21^{`} \mathrm{~W}$ ) a $41 \mathrm{~km}$.

Os dados foram processados com o software InterOcean Systems S4APP (programação e leitura dos instrumentos), o programa WaveWin de pósprocessamento e análise espectral e o software Matlab para tratamento gráfico. As direções de ondas foram agrupadas em intervalos de 22,5으 correspondendo aos intervalos entre os pontos cardeais, colaterais e subcolaterais.

O clima de ondas de uma região é definido e separado pelas características das ondas geradas localmente ou próximas á costa (Wind-sea, vagas) e por ondas geradas distantes à costa ou remotas (swell) (Caetano Neto et al. 1996; Holthuijsen, 2007) que são diferentes em frequência. Portanto, os estados de vagas (alta frequência) e swell (baixa frequência) foram definidos por períodos de onda inferiores e superiores a $10 \mathrm{~s}$, respectivamente, conforme sugerido por Araújo et al. (2003). Os parâmetros característicos para cada estado de mar foram obtidos através de análises em 3 histogramas bivariados, que contemplam: a) período de pico (eixo y) versus direção de pico (eixo $x)$; 2) altura significativa (eixo y) versus direção de pico (eixo $x$ ) e; 3 ) altura significativa (eixo y) versus período de pico (eixo x), de acordo com Araújo et al. (2003). Os eventos extremos foram identificados para valores de Hmáx maior/igual a $4 \mathrm{~m}$ (Araújo et al. 2003) registrados no ponto \#30.

As cartas sinóticas e cartas de ventos disponibilizadas pelo Centro de Hidrografia da Marinha do Brasil (www.marmil.gov.br) foram utilizadas para identificar os sistemas meteorológicos que originaram as pistas de ventos (fetch) e os principais campos de ondas registrados.

\section{Resultados}

A escala temporal de coletas de dados de ondas na plataforma interna rasa do Paraná foi de 408 dias (2842 registros) no ponto \#30, e de 488 dias (2389) medidos no ponto \#18 m. Houve alguma descontinuidade e falta de sobreposição entre os dados dos fundeios (Figura 2) porém, toda a base de dados obtida é qualitativamente confiável para a estatística do presente estudo. 


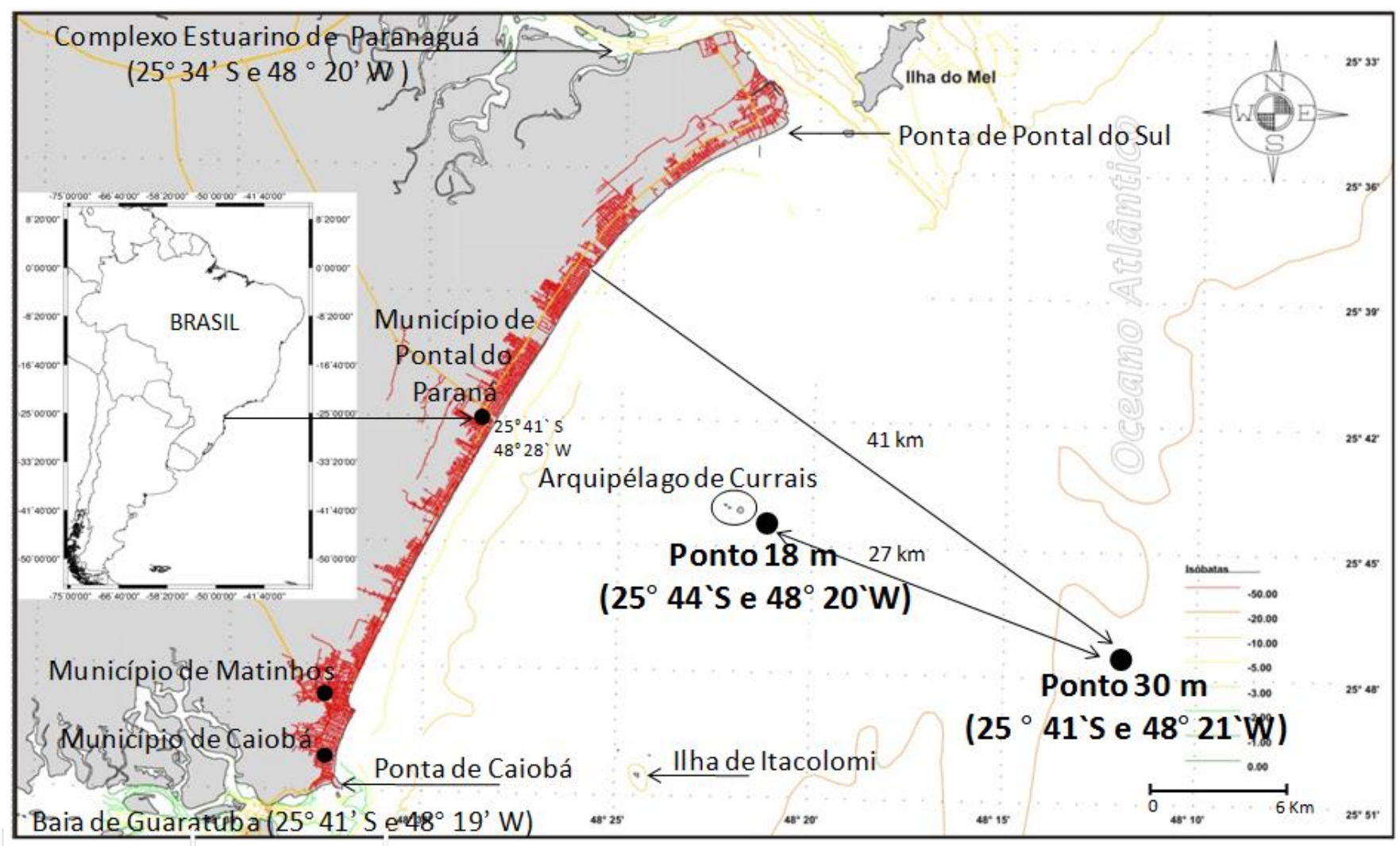

Figura 1 - Região central da linha de costa do Estado do Paraná. Destaque nos pontos de registro de parâmetros de ondas na plataforma interna rasa (Ponto $18 \mathrm{~m}$ e Ponto $30 \mathrm{~m}$ ).

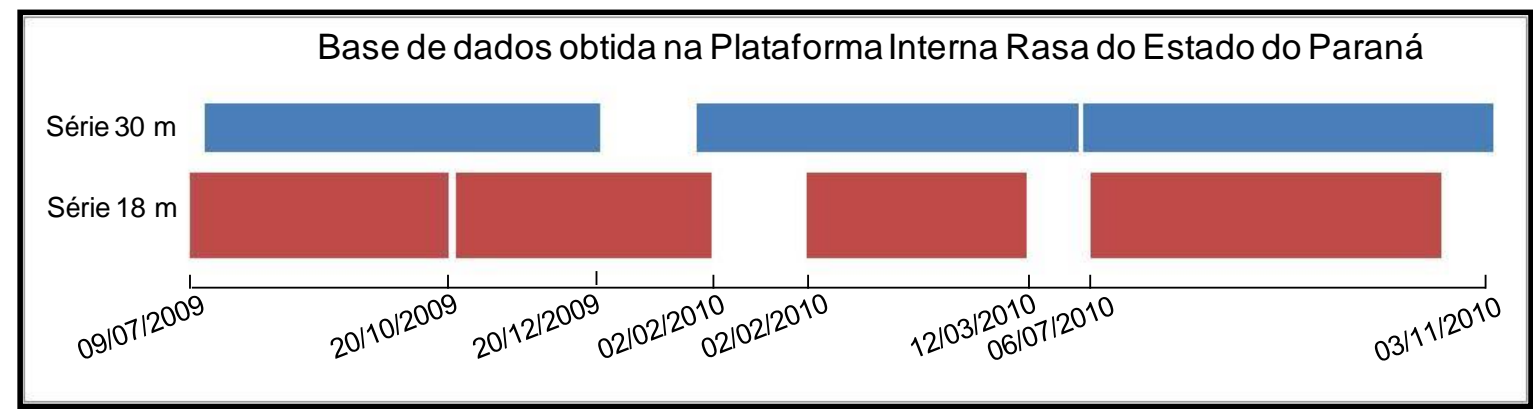

Figura 2 - Séries temporais obtidas (de 09/07/2009 a 03/11/2010) nos pontos \#30 e \#18.

\subsection{Características de ondas $(30 \mathrm{~m}$ e $18 \mathrm{~m})$}

Nas Figuras 3 e 4 estão apresentados os gráficos polares anuais dos dados de ondas medidos nos pontos \#30 e \#18, respectivamente. As principais direções de ondas (frequência maior que 10\%) foram: SSE (27,14\%), ESE $(21,26 \%)$, SE $(20,80 \%)$ e S $(12,81 \%)$ no ponto \#30 e; SSE $(28,22 \%)$, SE $(25,17 \%), S(21,15 \%)$ e ESE $(15,54 \%)$ no \#18.

A Figura 5 e a Figura 6 mostram a frequência relativa da altura significativa e período de pico para os pontos \#30 e \#18. Observa-se que há maior distribuição do número de classes de Hs no ponto \#30 que no \#18, assim como a moda é deslocada para classes de Hs com valor superior. Como esperado, a distribuição modal de Tp é semelhante. Há um pico de maior frequência registrado nas classes de Tp 4 a $5 s$, o que é discutido á frente.

\subsection{Características de ondas ( $30 \mathrm{~m}$ e $18 \mathrm{~m})$}

O estado de mar do tipo vagas ocorreu em $62,76 \%$ do tempo das observações no ponto $\# 30$ e $64,82 \%$ no ponto \#18. A ocorrência dos estados de swell ( $\mathrm{Tp} \geq 10 \mathrm{~s}$ ) no ponto \#30 foi de $37,24 \%$ e de $35,18 \%$ no $\# 18$. Um resumo das características dos estados de mar identificados a partir das Figuras 7 e 8 estão apresentados na Tabela 1 e 2. Observase que a direção de ondas é diferente apenas nos estados de vagas entre os pontos \#30 e \#18m. Há diminuição de Hs para ambos estados de mar entre os pontos e as classes de Tp possuem características semelhantes.

\subsection{Características sazonais}

Dos obtidos no ponto \#30, 30,27\% foram coletados na primavera, $11,02 \%$ no verão, $19,57 \%$ no outono e $39,14 \%$ no inverno. Já para o ponto \#18, 28,47 \% dos dados correspondem á primavera, $12,85 \%$ ao verão, $20,06 \%$ ao outono e $38,61 \%$ ao inverno. 


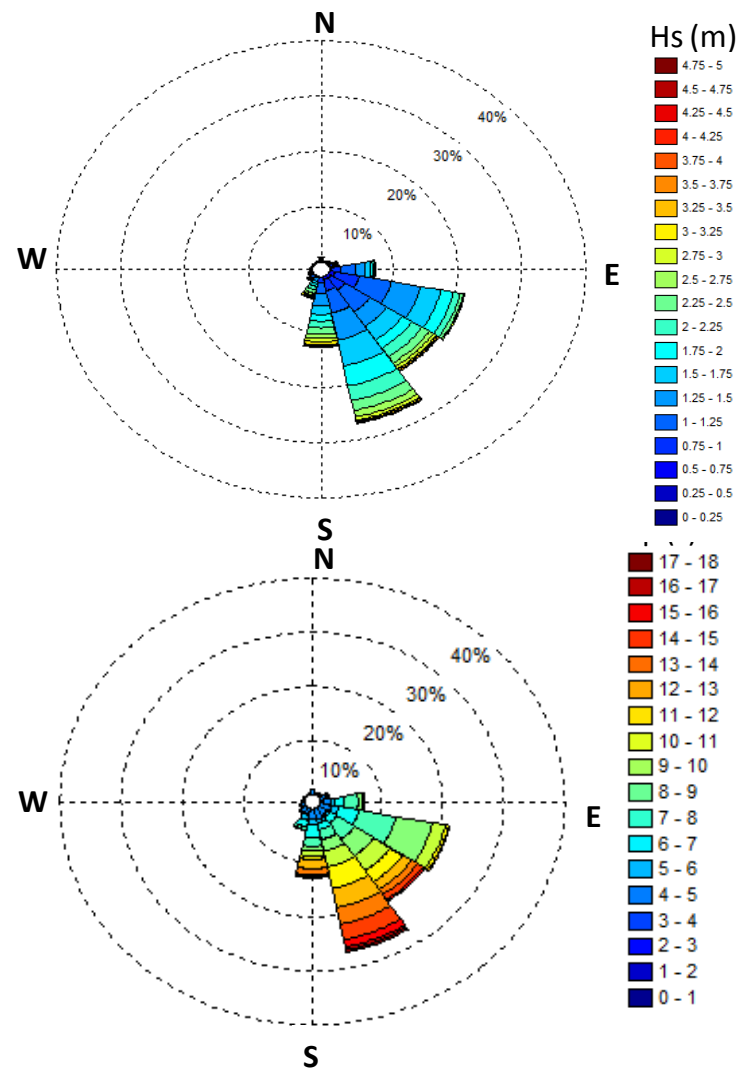

Figura 3 - Distribuição da altura e período de onda por direção no intervalo de 15/07/2009 a 03/11/2010 ( $n=2842)$ no ponto \#30.

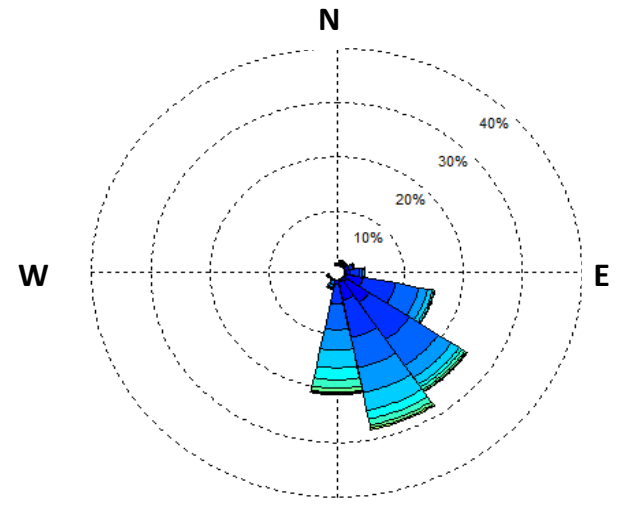

$\mathrm{Hs}(\mathrm{m})$
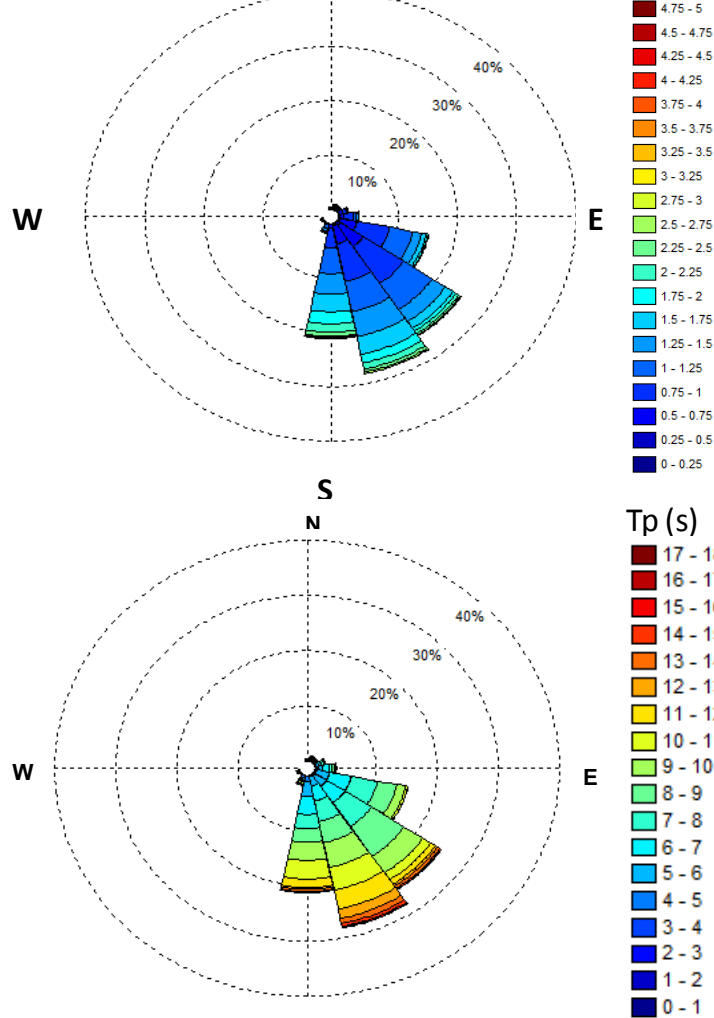

$\operatorname{Tp}(\mathrm{s})$

口 $17-18$

吕 $15-16$

$13-14$

$\square 12-13$

$\square 11-12$

$\square 10-11$

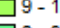

$8-9$

$7-8$

$\square 6-7$

$\square 5-6$

$4-5$

$3-4$
$2-3$

国 -2

Figura 4 - Distribuição da altura e período de onda por direção no intervalo de 09/07/2009 a 19/10/2010 ( $n=2389)$ no ponto \#18.
As Figuras 9 e 10 apresentam a distribuição direcional da altura e período de pico para cada estação. Em ambos fundeios a direção de ondas predominante na primavera foi SSE (31,28\% no \#30 e, 34,41\% no \#18). As maiores energias de ondas (valores mais altos de $\mathrm{Tp}$ ) estão associadas à direção SSE, tanto no ponto \#30 como no \#18 na temporada de primavera.

No verão a direção predominante de propagação de ondas foi ESE $(32,27 \%)$ no \#30 e SE $(39,09 \%)$ no \#18. Nesta temporada, no \#30, a propagação de ondas com valores de Tp mais altos foi com direção SSE, já no \#18 foi SSE e S.

As direções de propagação de ondas mais frequentes no outono foram SE $(32,73 \%)$ e SSE $(25,72 \%)$ no \#30, S $(28,60 \%)$ e SSE $(26,51 \%)$ no \#18. As direções de propagação de ondas SE e SSE estão associadas aos maiores valores de Tp medidos no \#30 e ESE e S no \#18 na temporada de outono.

A propagação de ondas SSE $(28,77 \%)$ e ESE $(25 \%)$ no \#30 tiveram as maiores ocorrências medida na temporada de inverno. No \#18 as maiores ocorrência de ondas foram SE $(28,74 \%)$, SSE $(25,49 \%)$ e ESE $(21,15 \%)$. Os maiores valores de $\mathrm{Tp}$ medidos no inverno foram registrados entre as direções SE a S, tanto no \#30 quanto no \#18.

Os eventos extremos ocorreram no outono (Hmáx 6,78 m, 08/04/2010), verão (Hmáx 6,47 m, 25/02/2010) e na primavera (Hmáx 6,07 m, 29/09/2009), referentes aos valores medidos no \#30. A única temporada onde não houve registros de valores de Hmáx superior a $6 \mathrm{~m}$ foi no inverno.

As ocorrências com valor de Hs maior/igual a $3 \mathrm{~m}$ (Hs $\geq$ $3 \mathrm{~m}$ ) obtidos no \# 30 estão distribuídos da seguinte maneira entre as temporadas: $3,84 \%$ na primavera; $1,27 \%$ no verão; $5,38 \%$ no outono; e $1,08 \%$ no inverno.

\subsection{Características sazonais dos estados de mar}

A temporada com a maior presença de swell foi o outono. Nas Tabelas 3 e 4 estão apresentadas as ocorrências dos estados de vagas e swell por temporadas medidas nos pontos \#30 e no \#18, respectivamente.

As características dos estados de mar identificados nas Figuras 11, 12 e 13 (para os dados de ondas no \#30) e nas Figuras 14, 15 e 16 (para os dados de ondas no \#18) estão resumidas na Tabela 5 (para o \#30) e Tabela 6 (para o \#18).

$\mathrm{Na}$ temporada de verão houve menor ocorrência de estados de swell em comparação com as outras temporadas. Com isso, a partir dos histogramas bivariados, não foi possível encontrar suficientes valores que possam caracterizar claramente os parâmetros de ondas para tais estados com significância estatística. Cabe ressaltar que há incidência de estados de swell (alta energia de ondas) e ondas extremas na temporada de verão, porém sem um padrão que permita caracterizar este estado para esta estação do ano. 


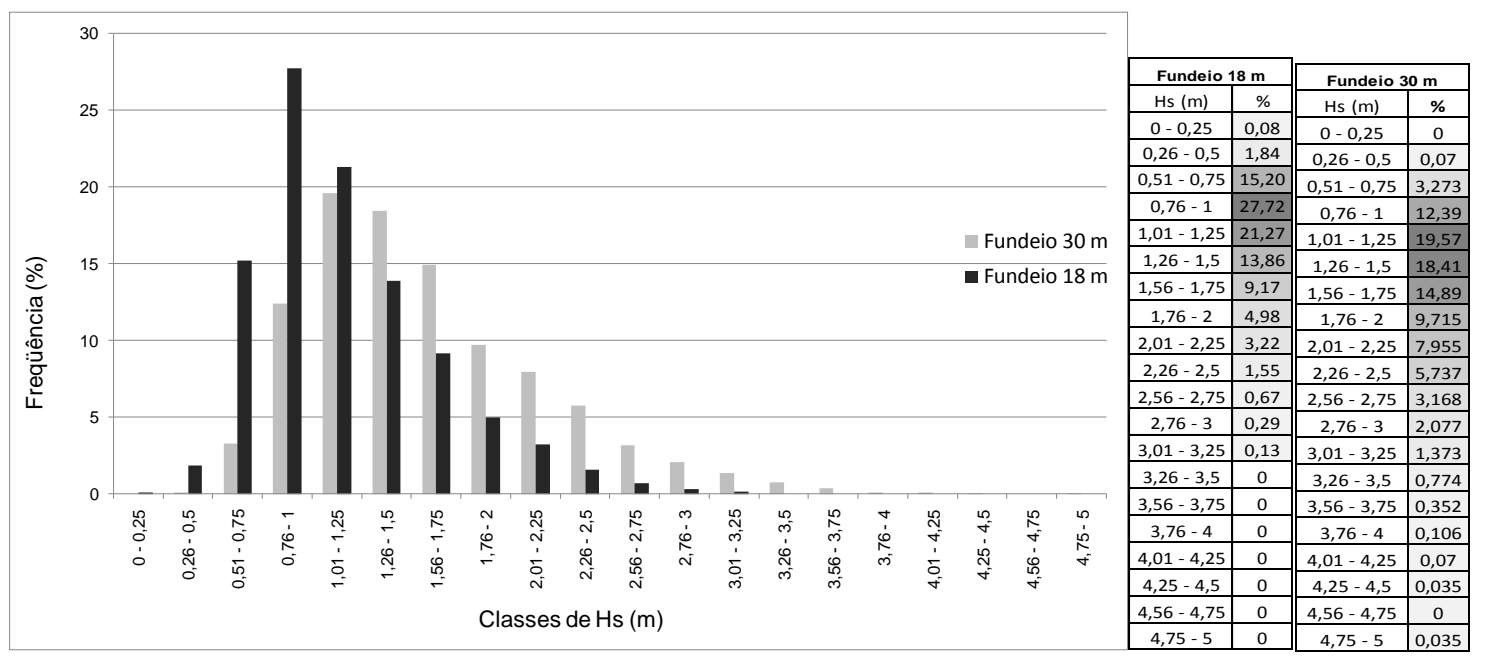

Figura 5. Frequência relativa da altura significativa (Hs) medida nos pontos \#30 e \#18.

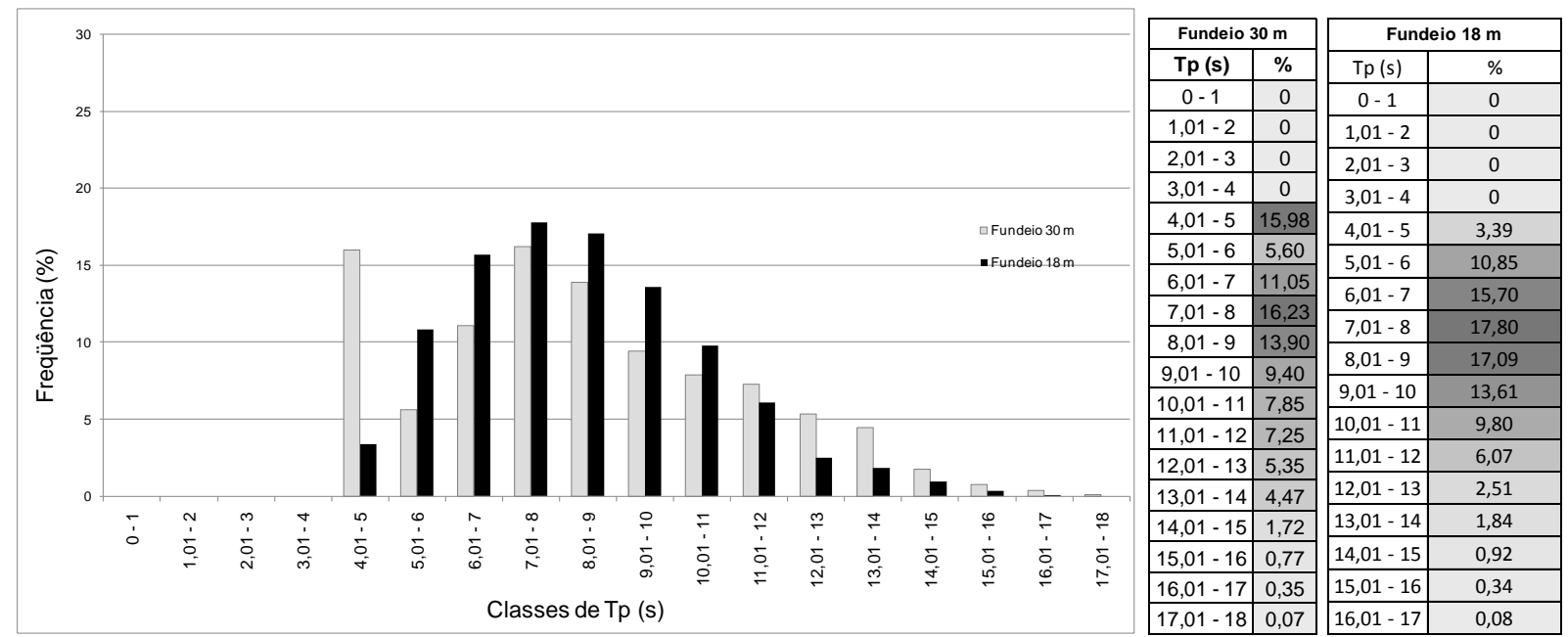

Figura 6. Frequência relativa do período de pico (Tp) medida nos pontos \#30 e \#18m.

Tabela 1. Estados de mar identificados no ponto \#30 a partir das correlações bivariadas, baseados na hipótese de espectro de ondas de um único pico

\begin{tabular}{|c|c|c|c|c|c|c|}
\hline \multirow{2}{*}{ S4 30m } & \multicolumn{3}{|c|}{ Vagas (SEA) } & \multicolumn{3}{c|}{ SWELL } \\
\cline { 2 - 7 } & $\boldsymbol{\emptyset}_{\mathrm{p}}$ & Hs (m) & Tp (s) & $\boldsymbol{\emptyset}_{\mathrm{p}}$ & Hs (m) & Tp (s) \\
\hline Parâmetros & $\mathrm{ESE}$ & $1,25-1,5$ & $8-9$ & $\mathrm{SSE}$ & $1,5-1,75$ & 11 \\
\hline
\end{tabular}

Tabela 2. Estados de mar identificados no ponto \#18 a partir das correlações bivariadas, baseados na hipótese de espectro de ondas de um único pico.

\begin{tabular}{|c|c|c|c|c|c|c|}
\hline \multirow{2}{*}{ S4 18m } & \multicolumn{3}{|c|}{ Vagas (SEA) } & \multicolumn{3}{c|}{ SWELL } \\
\cline { 2 - 7 } & $\boldsymbol{\emptyset}_{\mathrm{p}}$ & $\mathrm{Hs}(\mathrm{m})$ & $\mathrm{Tp}(\mathbf{s})$ & $\boldsymbol{\emptyset}_{\mathrm{p}}$ & $\mathrm{Hs}(\mathbf{m})$ & $\mathrm{Tp}(\mathbf{s})$ \\
\hline Parâmetros & $\mathrm{SE}$ & 1 & $8-9$ & $\mathrm{SSE}$ & $1-1,25$ & $10-11$ \\
\hline
\end{tabular}

\subsection{Origem dos principais estados de mar}

De acordo com a análise das cartas sinóticas, os principais fenômenos meteorológicos que deram origem à agitação marítima registradas nos pontos \#30 e \#18 foram: ciclones subtropicais (CS); frentes frias (FF) associadas ao sistema frontal; e alta (anticiclones) pós-frontal (APF).

Os estados de vagas foram gerados por pistas de ventos próximas à costa cuja distância foi geralmente inferior a $1000 \mathrm{~km}$. Os fenômenos meteorológicos que originaram 
Histograma Direcional de Período de Pico (S4 30m)

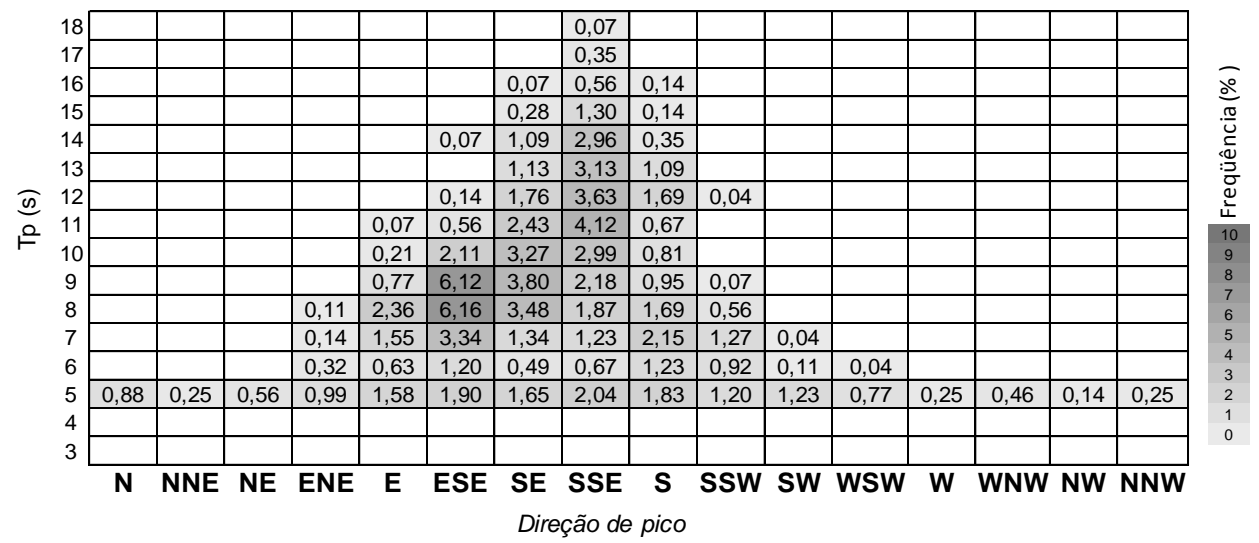

Histograma Direcional de Altura Significativa (S4 30m)

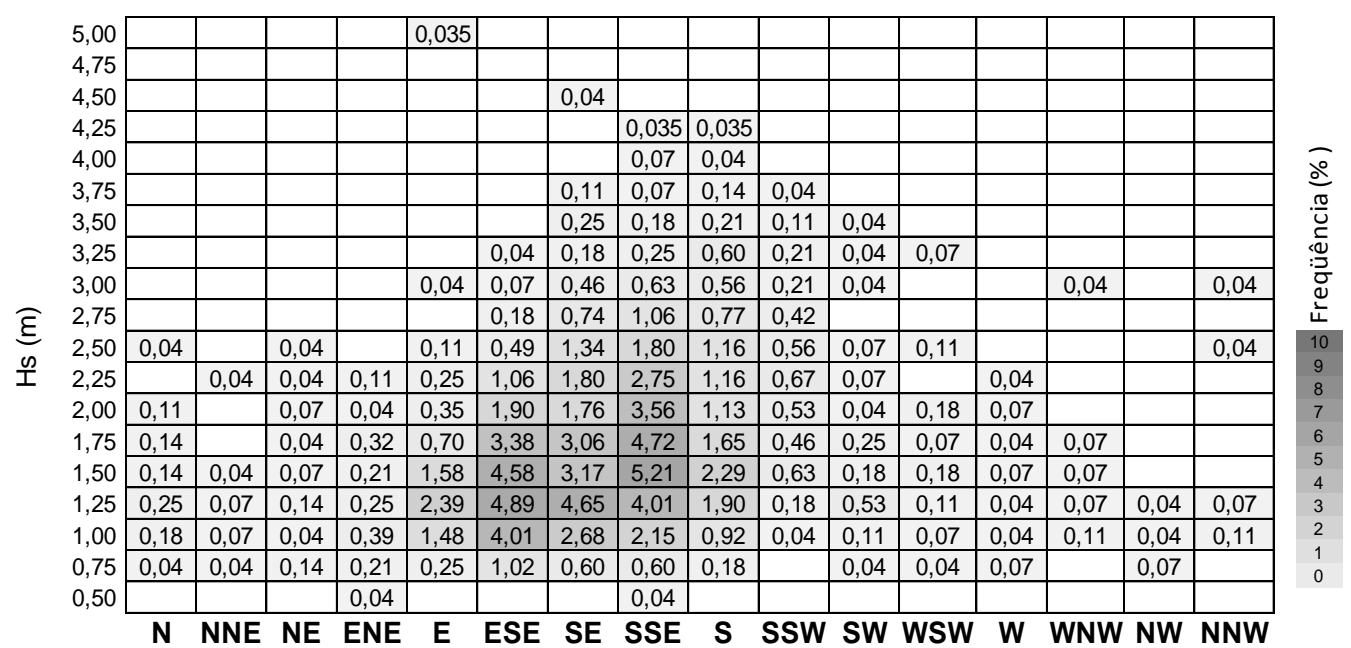

Direção de pico

Histograma de Altura Significativa x Período de Pico (S4 30m)

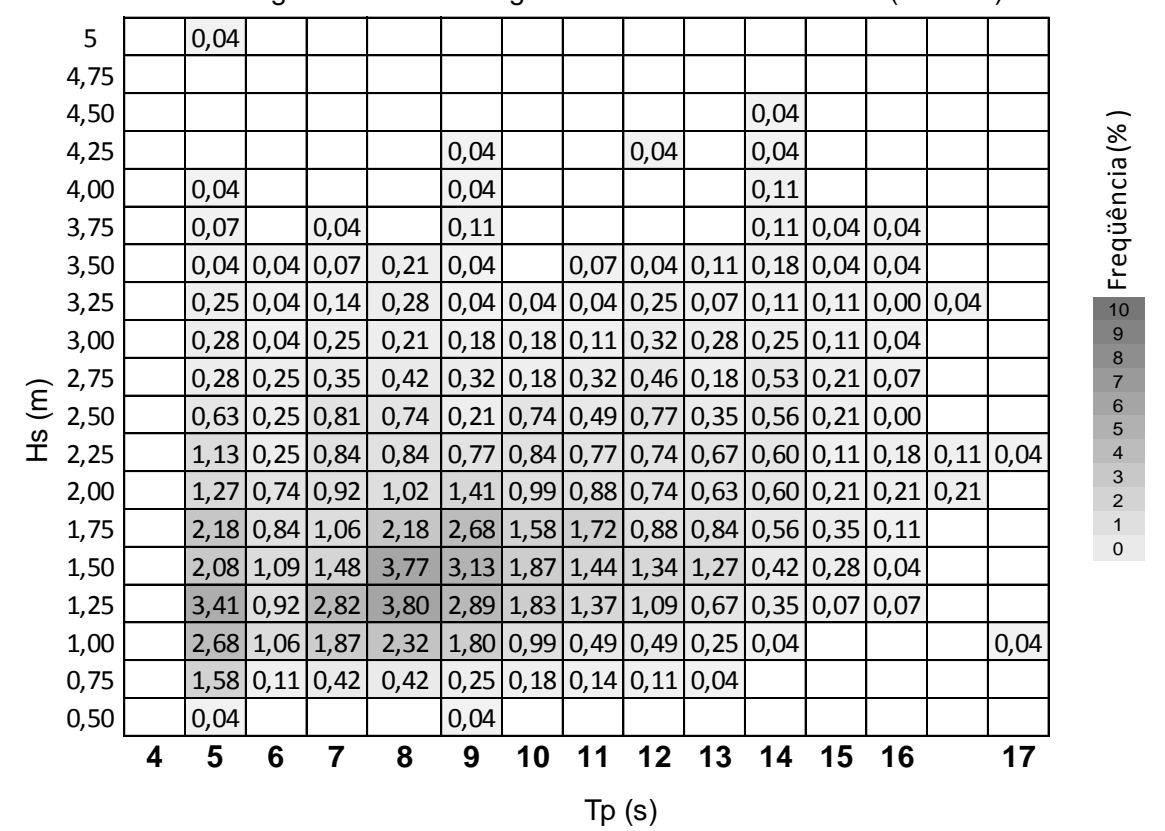

Figura 7. Histogramas bivariados anual de $\mathrm{Tp}(\mathrm{s})$ × Direção de pico, $\mathrm{Hs}(\mathrm{m})$ × Direção de pico e $\mathrm{Hs}(\mathrm{m}) \times \mathrm{Tp}(\mathrm{s})$, correspondentes aos dados originais medidos no ponto \#30, baseados na hipótese de espectro de ondas de um único pico. 
Histograma Direcional de Período de Pico x Direção de Pico (S4 18m)

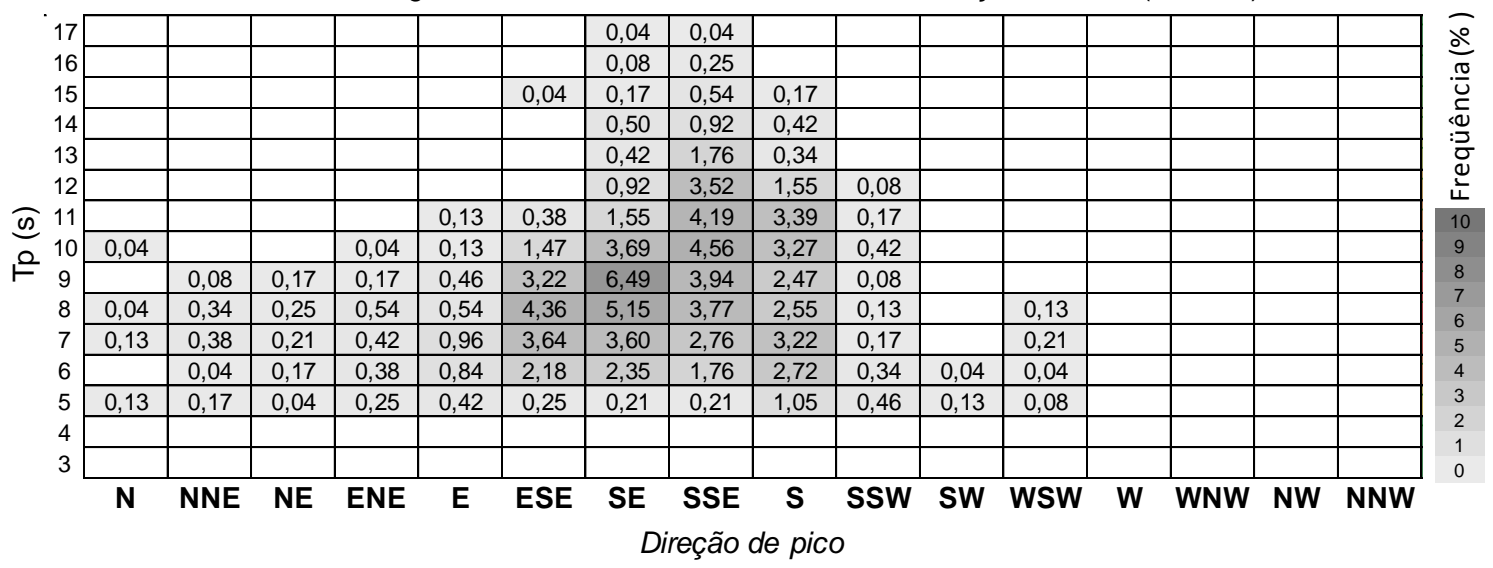

Histograma Direcional de Altura Significativa (S4 18m)
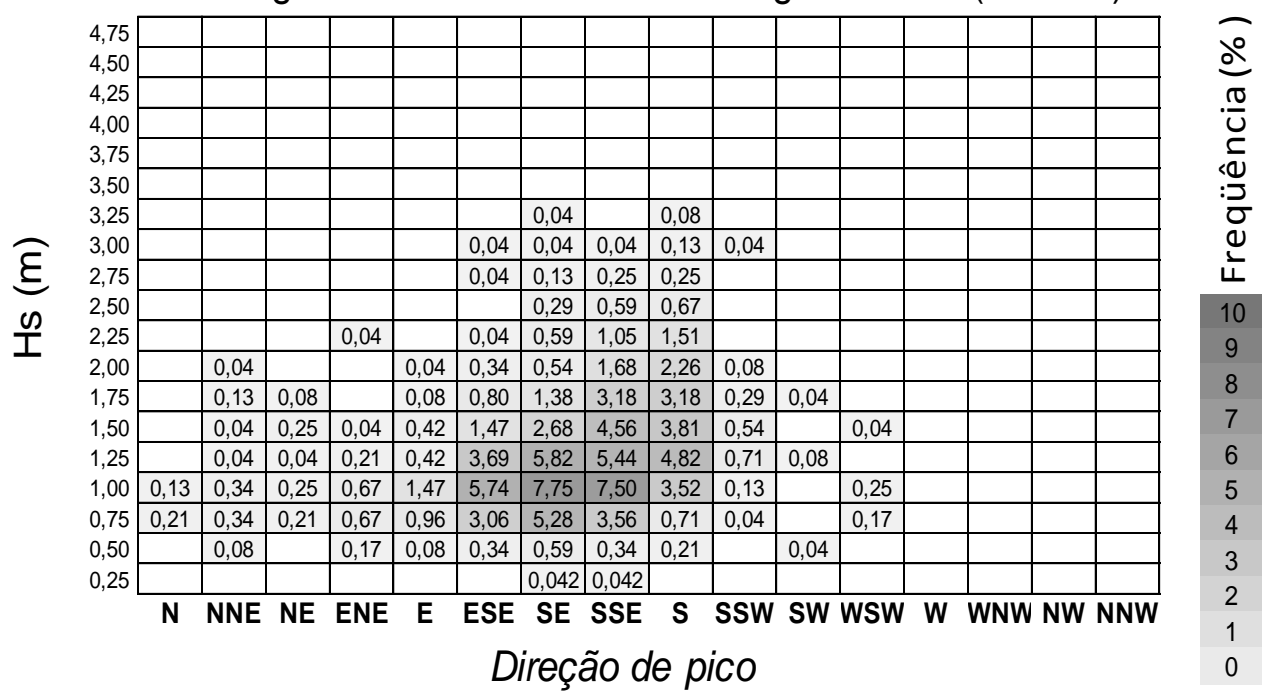

Histograma de Altura Significativa x Período de Pico (S4 18m)

\begin{tabular}{|c|c|c|c|c|c|c|c|c|c|c|c|c|c|c|}
\hline 3,25 & & & & & 0,04 & 0,04 & & & & & 0,04 & & & \\
\hline 3,00 & & & & 0,08 & 0,08 & 0,04 & & & & 0,04 & 0,04 & & & \\
\hline 2,75 & & & 0,08 & 0,04 & 0,13 & 0,04 & 0,17 & & & 0,04 & 0,04 & 0,04 & & \\
\hline 2,50 & & & 0,08 & 0,04 & 0,34 & 0,21 & 0,21 & 0,08 & 0,34 & 0,00 & 0,04 & 0,04 & 0,04 & \\
\hline 2,25 & & & 0,17 & 0,34 & 0,59 & 0,25 & 0,63 & 0,21 & 0,46 & 0,13 & 0,04 & 0,04 & & \\
\hline 2,00 & & & 0,29 & 0,80 & 0,88 & 0,75 & 0,50 & 0,59 & 0,75 & 0,34 & 0,17 & 0,04 & 0,04 & \\
\hline 1,75 & & 0,34 & 0,63 & 1,47 & 1,09 & 1,17 & 1,51 & 0,42 & 1,01 & 0,80 & 0,08 & 0,08 & & \\
\hline 1,50 & & 0,46 & 1,38 & 1,80 & 1,51 & 2,85 & 2,01 & 2,30 & 0,88 & 0,84 & 0,29 & 0,34 & 0,17 & 0,04 \\
\hline 1,25 & & 0,67 & 2,39 & 2,18 & 3,48 & 4,31 & 3,64 & 2,18 & 1,51 & 0,38 & 0,42 & 0,13 & & \\
\hline 1,00 & & 0,80 & 3,77 & 5,23 & 5,65 & 4,77 & 2,97 & 1,76 & 1,30 & 0,75 & 0,46 & 0,13 & 0,08 & 0,04 \\
\hline 0,75 & & 0,92 & 1,84 & 3,39 & 3,39 & 2,39 & 1,84 & 0,34 & 0,54 & 0,25 & 0,21 & 0,08 & & \\
\hline 0,50 & & 0,21 & 0,21 & 0,29 & 0,59 & 0,25 & 0,13 & 0,08 & 0,08 & & & & & \\
\hline 0,25 & & & & 0,04 & 0,04 & & & & & & & & & \\
\hline & 4 & 5 & 6 & 7 & 8 & 9 & 10 & 11 & 12 & 13 & 14 & 15 & 16 & 17 \\
\hline
\end{tabular}

Figura 8. Histogramas bivariados anual de $\mathrm{Tp}(\mathrm{s}) \times$ Direção de pico, $\mathrm{Hs}(\mathrm{m})$ × Direção de pico e $\mathrm{Hs}(\mathrm{m}) \times \mathrm{Tp}(\mathrm{s})$, correspondentes aos dados originais medidos no ponto \#18, baseados na hipótese de espectro de ondas de um único pico. 


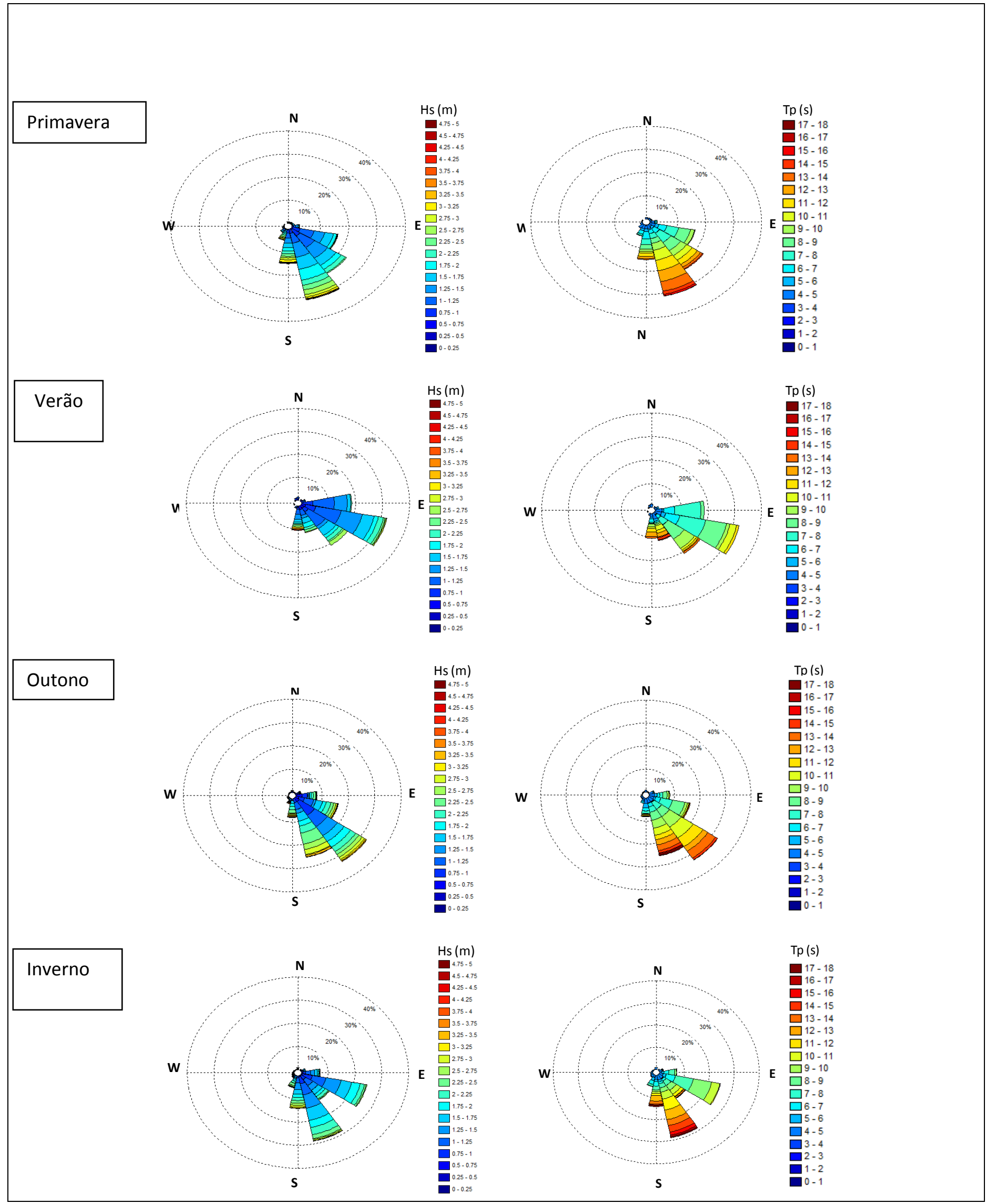

Figura 9. Características dos parâmetros de ondas (Hs, Tp e Dir $\varnothing)$ registrados no ponto \#30. 


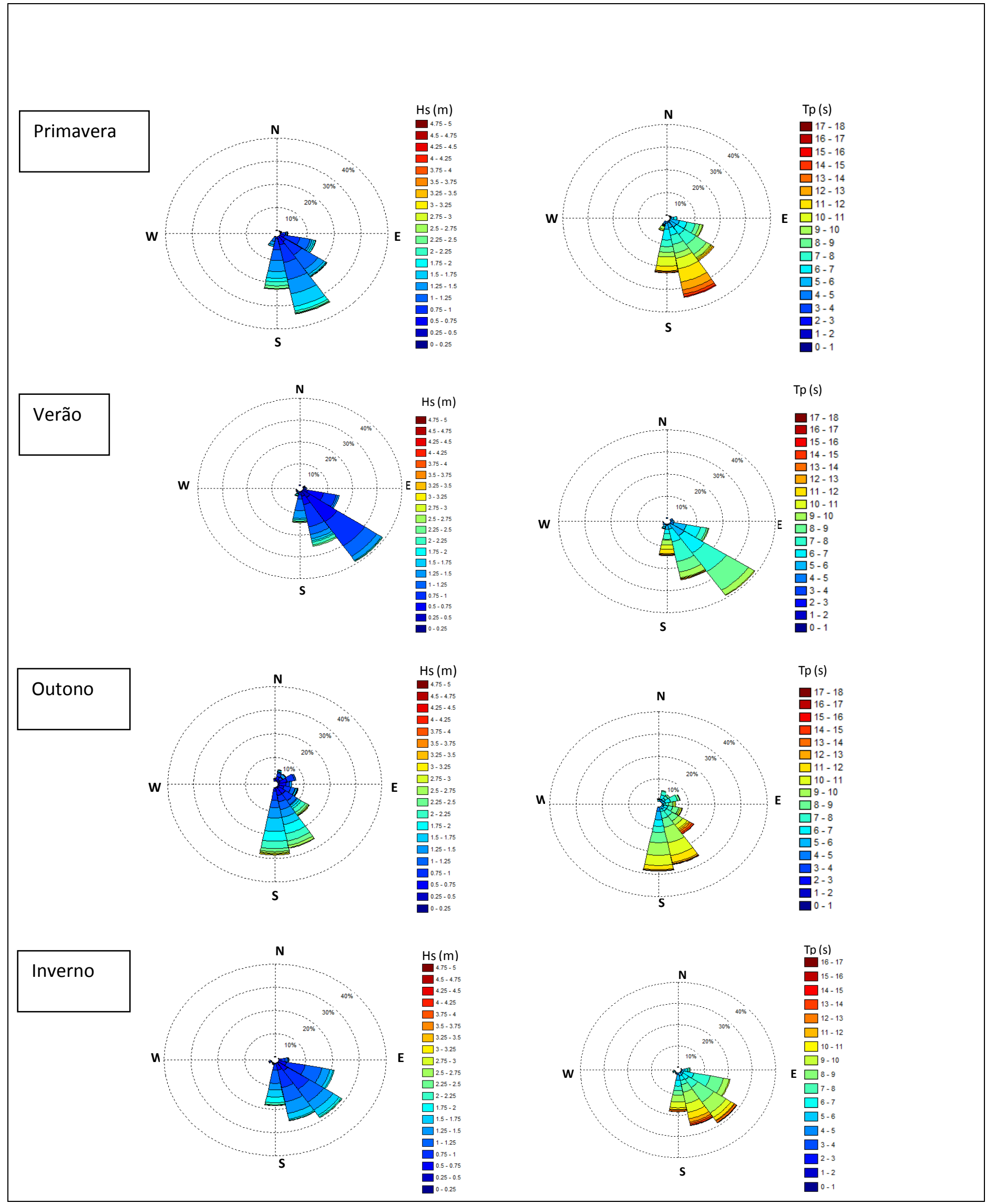

Figura 10. Características dos parâmetros de Ondas (Hs, Tp e Dir $\varnothing)$ registrados no ponto \#18. 
ondas de Tp abaixo de $10 \mathrm{~s}$ (alta frequência) foram: APF, FF e CS (este em fase inicial).

Já para estados de swell ( $\mathrm{Tp}>10 \mathrm{~s}$, baixa frequência) a principal origem foi em CS. Estes com pistas de ventos geograficamente posicionadas á mais de $1200 \mathrm{~km}$ da costa com cuja direção resultante de ventos foram SSE, SE, ESE e E.

Tabela 3. Características dos estados de mar sazonais identificados no ponto \#30 na plataforma interna rasa do Estado do Paraná.

\begin{tabular}{|c|c|c|c|c|}
\hline $\begin{array}{c}\text { Estados de } \\
\text { Mar a 30 } \mathbf{~ m}\end{array}$ & Primavera & Verão & Outono & Inverno \\
\hline Swell & $39,19 \%$ & $25,24 \%$ & $43,17 \%$ & $36,03 \%$ \\
\hline Vagas & $60,81 \%$ & $74,76 \%$ & $56,83 \%$ & $63,97 \%$ \\
\hline
\end{tabular}

Tabela 4. Características dos estados de mar sazonais identificados no ponto \#18 na plataforma interna rasa do Estado do Paraná.

\begin{tabular}{|c|c|c|c|c|}
\hline $\begin{array}{c}\text { Estados de } \\
\text { Mar a 18 m }\end{array}$ & Primavera & Verão & Outono & Inverno \\
\hline Swell & $36,03 \%$ & $14,33 \%$ & $40,08 \%$ & $38,94 \%$ \\
\hline Vagas & $63,97 \%$ & $85,67 \%$ & $59,92 \%$ & $61,06 \%$ \\
\hline
\end{tabular}

Tabela 5. Características dos estados de mar identificados com dados de ondas medidos no ponto \#30.

\begin{tabular}{|l|c|c|c|c|c|c|}
\hline \multirow{2}{*}{$\begin{array}{c}\text { S4 30m } \\
\text { Temporada }\end{array}$} & \multicolumn{3}{|c|}{ Vagas (SEA) } & \multicolumn{3}{c|}{ SWELL } \\
\cline { 2 - 7 } & $\boldsymbol{\emptyset}_{\mathrm{p}}$ & Hs (m) & Tp (s) & $\boldsymbol{\emptyset}_{\mathrm{p}}$ & Hs (m) & Tp (s) \\
\hline Primavera & ESE-SE & $1,25-1,75$ & $8-9$ & SSE & $1,5-2$ & $11-13$ \\
\hline Verão & ESE & $1,25-1,5$ & 8 & $\ldots$ & $\ldots$ & $\ldots$ \\
\hline Outono & ESE & 1 & 8 & SE & $1,75-2,25$ & $10-12$ \\
\hline Inverno & ESE & 1,5 & $7-8$ & SSE & $1,25-1,75$ & $11-12$ \\
\hline
\end{tabular}

Tabela 6. Características dos estados de mar identificados com os dados medidos no ponto \#18.

\begin{tabular}{|c|c|c|c|c|c|c|}
\hline \multirow{2}{*}{$\begin{array}{c}\mathrm{S} 418 \mathrm{~m} \\
\text { Temporada }\end{array}$} & \multicolumn{3}{|c|}{ Vagas (SEA) } & \multicolumn{3}{|c|}{ SWELL } \\
\hline & $\varnothing_{p}$ & $\mathrm{Hs}(\mathrm{m})$ & $\mathrm{Tp}(\mathrm{s})$ & $\emptyset_{p}$ & $\mathrm{Hs}(\mathrm{m})$ & $\mathrm{Tp}(\mathrm{s})$ \\
\hline Primavera & SE & $1-1,25$ & $8-9$ & SSE & $1-1,75$ & $11-12$ \\
\hline Verão & SE - SSE & $0,75-1$ & $7-8$ & & & \\
\hline Outono & SSE & $0,75-1,5$ & $8-9$ & SSE - S & $1,75-2,25$ & $10-11$ \\
\hline Inverno & ESE - S & $1-1,5$ & $7-9$ & SSE & $1-1,25$ & 10 \\
\hline
\end{tabular}

\subsubsection{ORIGEM DE EVENTOS EXTREMOS}

Foram identificados 87 dias (20,6 \%) com ondulações cujos valores de altura máxima (Hmáx) de onda foram maior/igual a $4 \mathrm{~m}$. Estes valores foram considerados (arbitrariamente neste estudo) como eventos extremos de ondas para o Estado do Paraná. Isto representou 221 dados obtidos no ponto \#30.

Os eventos extremos registrados com direções SE e SSE foram predominantemente originadas por CS (Tabela 7). $\mathrm{Na}$ direção $S$ foi observado que pouco menos de dois terços se originaram por CS e um terço por FF.

Os eventos extremos registrados com Tp inferior a $10 \mathrm{~s}$ corresponderam a $32,27 \%$ com origem em CS, e de $21,36 \%$ originados por FF (Tabela 8). Já para os eventos extremos com Tp maior/igual a $10 \mathrm{~s}$ (swell extremo) foram 100\% originados por pistas de ventos formadas por CS (Tabela 8). Os CS corresponderam aos registros de ondas com valores mais elevados de densidade espectral (maior energia de ondas) em relação às geradas pelas FF.

Os CS, associados aos eventos extremos, localizam-se em torno de $30^{\circ} \mathrm{S} / 55^{\circ} \mathrm{W}$ e em $25^{\circ} \mathrm{S} / 50^{\circ} \mathrm{W}$ (Figura 11) e se deslocam deslocaram para ESSE e SE acompanhados por um anticiclone na região da Patagônia (Argentina), localizado a SSW, S ou SE das depressões atmosféricas. O gradiente de pressão formado tendeu a originar pistas de ventos a princípio próximas à costa, justamente sobre a área da plataforma e talude do arco costeiro Cabo Frio (RJ) e Cabo de Santa Marta (SC). Este cenário definiu 32,27\% dos registros extremos com períodos inferiores a $10 \mathrm{~s}$ (vagas). Quando a região com maior gradiente de pressão se encontrou a mais de $1000 \mathrm{~km}$ do litoral paranaense as ondas medidas apresentaram $\mathrm{Tp} \geq 10 \mathrm{~s}$, correspondendo a $41 \%$ dos eventos extremos (Hmáx $\geq 4 \mathrm{~m}$ ).

\section{Discussão}

Houve a identificação de um número suficiente de tempestades para poder caracterizar o clima de ondas em escala interanual, conforme proposto por Holthuijsen (2007). A sazonalidade é definida pela formação e posicionamento geográfico dos centros de pressão e sistemas atmosféricos, tendo maior energia de ondas no outono e primavera, coincidindo com a ciclogênesis de ciclones proposto por Reboita et al. (2010).

O menor e maior período de onda registrado foi de 4 s e 18 $\mathrm{s}$, respectivamente. Com isso as ondas começam a sentir o fundo a aproximadamente $34 \mathrm{~m}$ de profundidade, para os menores valores de períodos, e aos $152 \mathrm{~m}$, para os maiores valores de período. Dessa forma, os dados de ondas obtidos já possuem algum processo de refração de ondas.

$\mathrm{Na}$ plataforma interna rasa paranaense, independentemente da direção de origem, a energia de onda de baixa frequência e alta densidade espectral foi registrada apenas nas direções entre ESE a S no ponto \#30, na direção entre SE a S no ponto \#18 e, utilizando os dados apresentados por Porto Lima (2008), na direção entre SE e SSE a $10 \mathrm{~m}$ de profundidade. A amplitude de distribuição dos ângulos de ondas diminui à medida que o trem de ondas avança em direção à costa e isto é explicado pela propriedade não dispersiva das ondas em águas rasas (KOMAR, 1998),

Através dos estudos pretéritos de ondas foi possível comparar e observar as diferenças nas direções de incidência de ondas apresentadas. Pôde-se identificar que nestes estudos os autores apresentaram características de ondas pontuais que representam apenas o conjunto de estados de mar que foram possíveis de serem medidos na escala temporal que cada autor dispôs. Bandeira (1974), entre abril de 1972 e março de 1973, obteve como direção mais frequente $\operatorname{ESE}(14,48 \%)$, direção, predominante somente na temporada de verão registrada a $30 \mathrm{~m}$ pelo presente estudo. Portobrás (1983), entre agosto e dezembro de 1982, obteve direções de ondas preferenciais de SSE e SE a 16,5m de profundidade, que está de acordo 
Tabela 7. Estatística da origem das direções de propagação de ondas medidas a $30 \mathrm{~m}$ na plataforma interna rasa do Paraná.

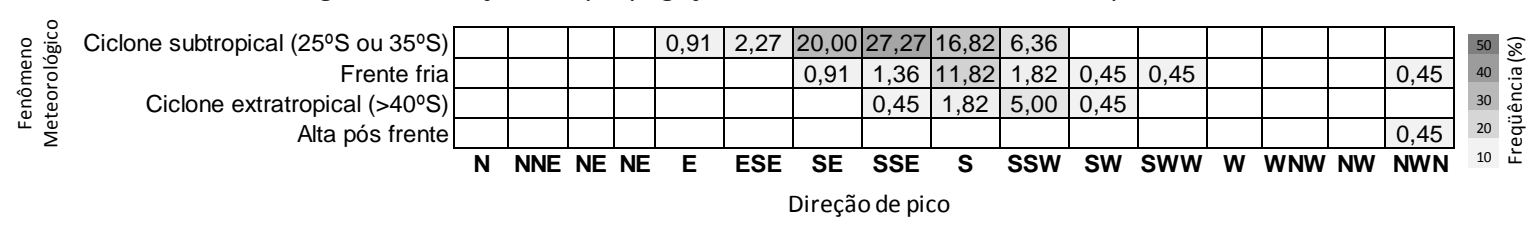

Tabela 8. Características de origem dos estados de mar a partir dos fenômenos meteorológicos monitorados sobre o Oceano Atlântico Sul ocidental.

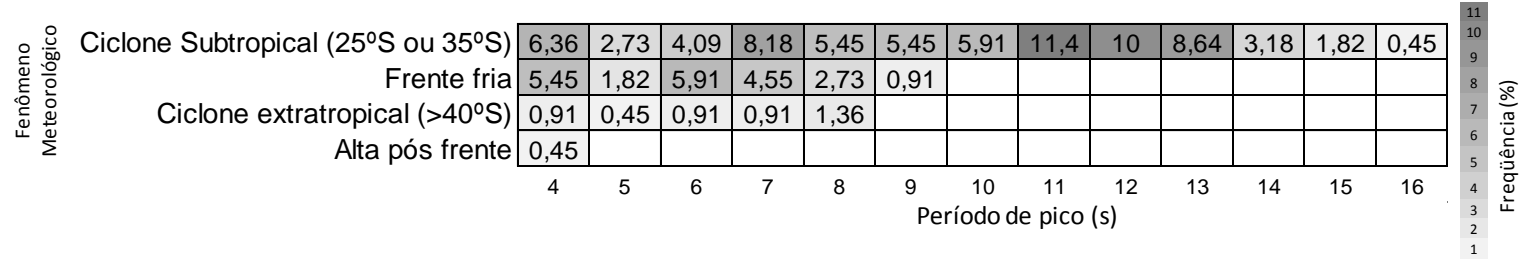
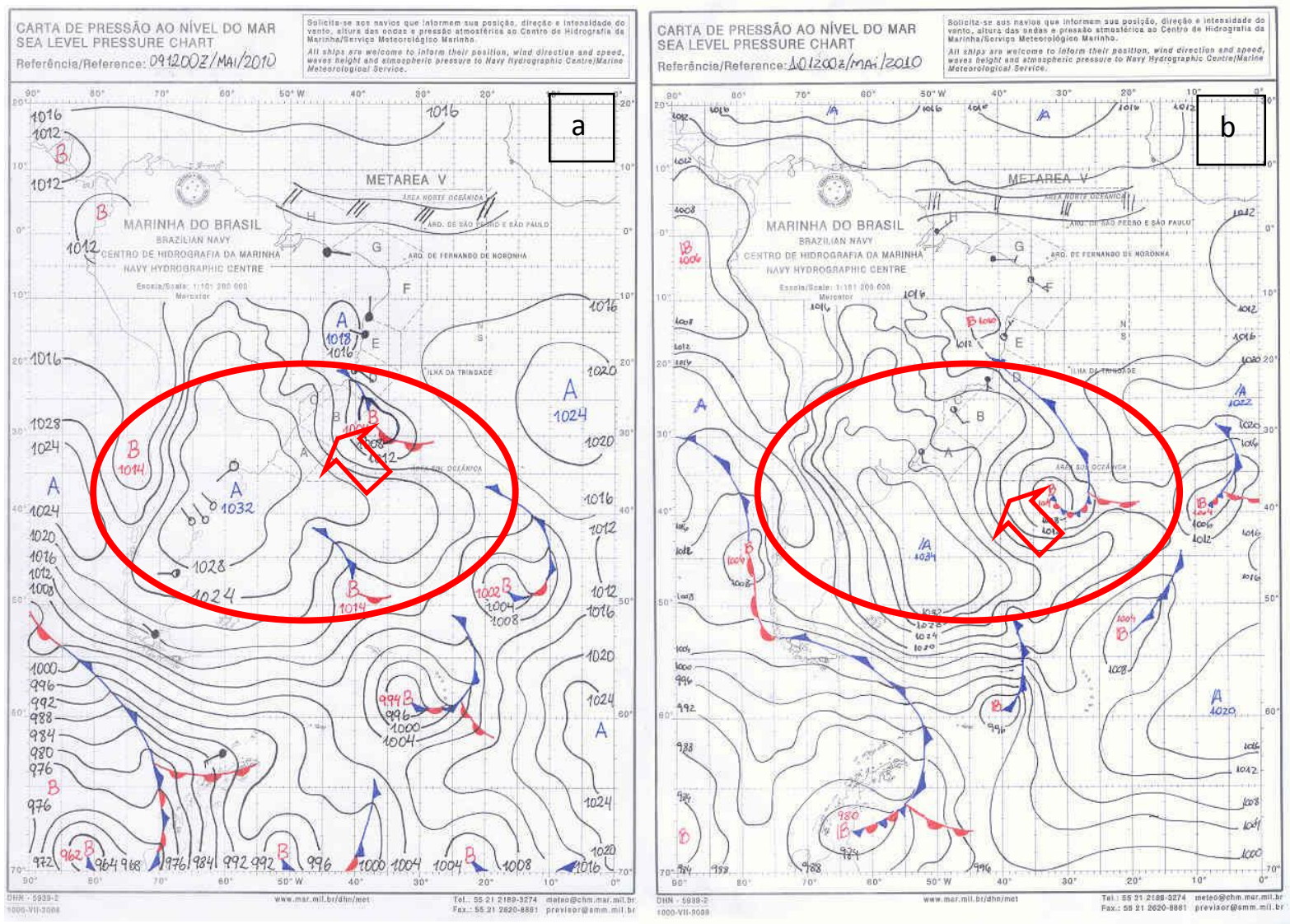

Figura 11. Diagrama de deslocamento de centros de pressão com base nas cartas sinóticas do Centro de Hidrografia da Marinha do Brasil para os dias 09/05/2010, $00 Z$ (a) e 10/05/2010, $00 Z$ (b), exemplificando as formações de baixas pressões atmosféricas em $45^{\circ} \mathrm{W}$ e $25^{\circ} \mathrm{S}$, que se deslocaram para ESE e/ou SE do continente, acompanhadas por um anticiclone posicionado a sul ou sudoeste deste (destacados no círculo). No cenário a) a pista de ventos se encontra a menos de $1000 \mathrm{~km}$ da costa, originando evento extremo de vagas. Já no cenário b) a pista de se encontra a mais de $1000 \mathrm{~km}$ da costa, e assim, ondas de baixa frequência e alta densidade espectral foram possíveis de serem registradas no ponto \#30.

com as encontradas por Porto Lima (2008) (em períodos de registros entre outubro de 2006 e janeiro de 2008) e o presente estudo. Marone e Camargo (1994), em curtos registros de parâmetros de ondas entre a ilha da Galheta e o Balneário Atami, encontraram no verão direção predominante de SE e no inverno SSE, o que é similar ao que foi medido a $18 \mathrm{~m}$ e a $30 \mathrm{~m}$, respectivamente, pelo presente trabalho nas mesmas temporadas apresentadas.
No trabalho de Martins (2002), realizado entre janeiro de 2000 e junho de 2001, as maiores frequências de incidência de ondas medidas no Balneário Atami foram $S$ e $S E$, direções que foram medidas com mais frequência somente na temporada de outono pelo presente estudo

Na plataforma interna rasa do Estado do Paraná há predominância de estados de vagas (espectro de ondas de alta frequência e baixa densidade de energia) sobre os 
estados de swell (espectro de ondas de baixa frequência e alta densidade de energia). Entre os estados de vagas houve a reorientação por refração do trem de ondas dos 30 $\mathrm{m}$ aos $18 \mathrm{~m}$, de ESE para SE, respectivamente. O processo de refração causa a diminuição das alturas de $30 \mathrm{~m}$ para os $18 \mathrm{~m}$ de profundidade, oposto ao que seria esperado em uma zona de transição entre águas profundas e rasas. Como processos de refração são mais intensos com ondas mais longas, a perda de energia é mais nítida no swell, cuja altura significativa passa de 1,75 m (\#30) para 1,25 m (\#18). Na figura 10 é possível identificar que as classes de Tp possuem maiores valores no ponto \#30 do que no \#18. A única direção de ondas onde não ocorre diminuição de altura entre \#30 e \#18 é SSW, que se propagam mais paralelamente à costa.

Os ciclones subtropicais foram os sistemas meteorológicos mais importantes na formação de pistas de ventos capazes de gerar eventos extremos e os principais estados de swell que incidiram na plataforma interna. Segundo Beu e Ambrizzi (2006) sistemas são menos frequentes que os ciclones extratropicais e são mais significativos nas estações de transição, ou seja, outono e primavera. Foi exatamente nestas estações onde se concentraram os eventos extremos de ondas registrados.

As cristas de marcas de ondulações nas estruturas sedimentares orientadas para SE, identificadas por Veiga (2005), coincidem com a direção de ondas dos dois eventos extremos mais energéticos registrados no presente estudo. A origem destas ondas encontra-se na ação de ciclones subtropicais e não da passagem de frentes frias como sugeriu o autor.

Os ciclones extratropicais com formação ao SE da costa da Argentina descritos por Reboita et al. (2009) e Reboita et al. (2010) foram observados no presente estudo com direções de pistas de ventos de SW, SSW e S. Rocha et al. (2004) observaram que a passagem de ciclones extratropicais sobre a costa sul brasileira esteve associada a ondas com alturas acima de $5 \mathrm{~m}$ e direção SW. A costa do Estado do Paraná é abrigada da maioria do swell de SW provenientes de ciclones extratropicais.

As frentes frias foram geralmente identificadas com pistas de ventos sobre a plataforma continental e talude sul brasileiro, fazendo com que os campos de ondas gerados não tenham tempo para dispersar frequências características de estado de swell para a costa paranaense. Geralmente as pistas de ventos de frentes frias estiveram muito próximas da área de estudo, e geraram ondas que apesar de possuírem alturas elevadas tinham pequeno período. Calliari e Klein (1993) afirmam que a dinâmica praial na costa sul brasileira é regulada, principalmente, pelos fenômenos associados à passagem de frentes meteorológicas ou frentes polares. Ao correlacionar o levantamento da incidência de frentes frias com os dias em que houve agitação marítima acentuada na região da costa paranaense Quadros et al. (2007) observaram que poucos sistemas frontais originaram tais agitações nas praias estudadas. A maior intensificação de incidência de frentes frias é no inverno (AYOADE, 2004) e nas temporadas (2009 e 2010) registradas o inverno foi a temporada com as menores ocorrências de eventos extremos segundo os valores propostos por Araújo et al. (2003).

Por outro lado, as frentes frias, acompanhadas de ventos de $\mathrm{S}$, tendem a acumular água contra a costa e gerar a intensificação dos efeitos erosivos nas praias. Assim sendo, ocorre a falsa impressão que estes momentos estão relacionados com eventos extremos de alta energia de ondas, por ter um caráter destrutivo para as obras costeiras.

Alves e Melo (2001) identificaram que os estados de swell na costa de São Francisco do Sul (SC) estão associados às tempestades que se propagam ao longo da costa da América do Sul e derivaram para o oceano ao longo dos paralelos 20 ㅇ S e 40 ㅇ. Alves e Melo (2001) observaram que as pistas de ventos foram formadas a uma distância superior a $1000 \mathrm{~km}$ do local de estudo. Esta característica de geração de ondas está de acordo com o que foi identificado no presente estudo. Tais pistas de ventos puderam ser identificadas com distância de até $2500 \mathrm{~km}$ da área de estudo, com intensidade de ventos de até 100 $\mathrm{km} / \mathrm{h}$ e duração de aproximadamente 72 hs. Esta característica de ciclones no oceano é similar as detalhadas por Reboita (2008) e Reboita et al. (2010).

Os estados de swell foram mais frequentes no outono, tendo maiores valores de densidade espectral registrados no outono e primavera, ratificando o histórico das "ressacas" mais intensas registradas nestas temporadas (SUDERHSA, 2007). As maiores variações volumétricas identificadas por Quadros et al. (2007) também coincidem com os padrões de energia de ondas apresentados neste estudo.

Os espectros de ondas relativos aos estados de swell medidos a $30 \mathrm{~m}$ coexistem com mar de ventos locais, ou seja, há picos de alta e baixa frequência coexistindo. Nas temporadas de primavera, outono e inverno foram possíveis detectar às vezes três ou mais picos em um mesmo espectro de ondas de baixa frequência, fato que poderia ser explicado pelas observações de Rodrígues e Guedes Soares (1999) de que muitas vezes as ondas de ventos próximas a costa se desenvolvem na presença de algumas baixas frequências espectrais (swell), provindas do oceano aberto. $\mathrm{Na}$ região da plataforma interna paranaense foram raros tais espectros de ondas predominantemente com pico único (relacionados ao outono e primavera), já que a costa sul brasileira está muito próxima das áreas de geração destes tipos de ondas.

\section{Conclusão}

O regime de ondas na plataforma interna rasa do Estado do Paraná é dominado por ondas de alta frequência (vagas) formadas por ventos próximos à costa $(<1000 \mathrm{~km}$ da linha de costa do Estado do Paraná) e direção predominante de propagação SSE.

Os principais estados de mar incidentes na costa paranaense e ondas de alta energia são mais determinados 
pelo posicionamento das pistas de ventos do que pela passagem de frentes frias.

Os ciclones subtropicais são os sistemas meteorológicos mais importantes para a incidência de alta energia de ondas na costa paranaense. Os estados de swell na costa do Paraná são predominantemente originados por ciclones subtropicais. Em caráter de manejo costeiro e consequências erosivas na costa, as temporadas de primavera e outono são importantes para caracterizar os fenômenos de caráter destrutivo.

Existe uma acentuada variação sazonal como também evidências de variações inter-anuais dos principais parâmetros incidentes de ondas.
Agradecimentos: Os autores agradecem o suporte do coordenador do Grupo de Física Marinha Dr. Maurício Noernberg o qual tem suporte do CNPq (480428/2007-7), assim como, os professores Dr. Ricardo de Camargo, Dr. Carlos Roberto Soares, Dr. Eduardo Siegle e aos colegas do GFM MSc. Clécio José Lopes de Quadros, MSc. Marcos Gandor Porto Lima e equipe de mergulho. O Dr. Eduardo Marone agradece o suporte da CAPES (BEX 1186/10-8) para o ES no INOGS, Trieste, Itália.

\section{Referências bibliográficas}

ALVES J.H.G.M., MELO E. 2001. Measurement and modeling of wind waves at the northern coast of Santa Catarina, Brazil. Brazilian Journal of Oceanography, 49, 13-28.

ALVES J.H.G.M., RIBEIRO O.E., MATHESON G.S.G., LIMA J.A.M., RIBEIRO C.E.P. 2009. Reconstituição do clima de ondas no sulsudeste brasileiro entre 1997 e 2005. Revista Brasileira de Geofísica, 27(3), 427-445.

ARAÚJO C.E.S., FRANCO D., MELO E., PIMENTA F. 2003. Wave Regime Characteristics of The Southern Brazilian Coast. Proceedings of the sisth international conference on coastal and port engineering in developing countries, Proceedings COPEDEC VI, Colombo, Sri Lanka. Paper 097; p 15.

AYOADE J.O. 2004. Introdução à climatologia para os trópicos. Tradução de Maria Juraci Zani dos Santos; revisão de Suely Bastos. 10a ed. Rio de Janeiro: Bertrand Brasil.

BANDEIRA J.V. 1974. Estudo estatístico das ondas ao largo da Baía de Paranaguá, 1974. Dissertação (Mestrado em Oceanologia) - Universidade Federal do Rio Grande do Sul, Porto Alegre.

BEU C.M.L., AMBRIZZI T. 2006. Variabilidade interanual e intersazonal da frequência de ciclones no Hemisfério Sul. Revista Brasileira de Meteorologia, 21 (1), 44-55.

CAETANO NETO E.S., INNOCENTINI V., ROCHA R.P. 1996. Um sistema de previsão de tempo e de ondas oceânicas para o Atlântico Sul. Brazilian Journal of Oceanography, 22(1), 35-46.

CALLIARI L.J., KLEIN A.H. 1993. Características morfodinâmicas e sedimentológicas das praias oceânicas entre Rio Grande e Chuí, RS. Pesquisas, 20 (1), 48-56.

CALLIARI L.J., MUHERE D., HOEFEL F.G., TOLDO JR E. 2003 Morfodinâmica praial: uma breve revisão. Brazilian Journal of Oceanography, 51, 63-78.

FYFE J.C. 2003. Extratropical Southern Hemisphere Cyclones: Harbingers of Climate Change? Journal of Climate, 16, 28022805.

GOYA S.C., TESSLER M.G. 2000. Variações morfológicas espaçotemporais entre as praias de Cibratel e Itanhaém-Suarão, Estado de São Paulo. Revista Brasileira de Oceanografia, 48 (2), 151-166.

HOLTHUIJSEN L.H. 2007. Statistics. In: Waves in Oceanic and Coastal Waters. New York: Cambridge University Press. 56105.

IAPAR. 1978. Manual agropecuário para o Paraná. IAPAR Fundação Instituto Agronômico do Paraná, 90p.

INTEROCEAN, S. 1994. S4 Current Meter: Users'Manual. San Diego: InterOcean Systems, 180p.

INPH. 1985. Medições de ondas em Paranaguá/PR - 01/09/1982 a 31/08/1983.
KLEIN A.H.F., SANTANA G.G., DIEHL F.L., MENEZES J.T. 2003. Analysis of Hazards Associated with Sea Bathing: Results of Five Years Work in Oceanic Beaches of Santa Catarina State, Southern Brazil. Journal of Coast Research, SI 35 (Proceedings of the Brazilian Symposium on Sandy Beaches: Morphodynamics, Ecology, Uses, Hazards and Management), 107-116. Itajaí, SC - Brazil, ISSN 0749-0208.

KOMAR P.D. 1998. Beach Processes and Sedimentation. 2nd ed. Prentice Hall, Inc. New Jersey, USA.

MARONE E., CAMARGO R. 1994. Marés meteorológicas no litoral do Estado do Paraná: O evento de 18 de agosto de 1993. Nerítica, 8 (1-2), 73-85.

MARTINS G.J. 2002. Dinâmica da zona de arrebentação e suas potenciais consequências no transporte de sedimentos na costa adjacente à desembocadura sul do completo estuarino de Paranaguá-Pr. Dissertação (Mestrado em Geologia Ambiental) - Setor de ciências da terra, Universidade Federal do Paraná, Curitiba.

MCTAGGART-COWAN R., BORSAT L.F., DAVIS C.A., ATALLAH E.H., GYAKUM J.R., EMANUEL K. 2006. Analysis of hurricane Catarina (2004). Monthly Weather Review, 134, 3029-3053.

PARISE C.K., CALLIARI L.J., KRUSCHES N. 2009. Extreme storm surges in the south of Brazil: atmospheric conditions and shore erosion. Brazilian Journal of Oceanography, 57 (3), 175188.

PORTOBRAS. 1983. Campanha de medições de ondas em Paranaguá - PR, período 21.08.1982 a 21.01.1993. Rio de Janeiro, Inst. Psq. Hidrog. (INPH), Div. Lev. (DIDELE), 23p.

PORTO LIMA M.G. 2008. Controle da erosão em praias arenosas pelo método de recifes submersos: praia brava de matinhos PR. Dissertação (Mestrado em Sistemas Costeiros e Oceânicos) - Centro de Estudos do Mar, Universidade Federal do Paraná, Pontal do Paraná.

QUADROS C.J.L., MARONE E., ÂNGULO R.J., MARITINS G.J., NETTO JR J.P.B. 2007. Dinâmica morfosedimentar associada à incidência de sistemas frontais em duas praias do litoral paranaense. Boletim Paranaense de Geociências, UFPR, 60, 65-74.

REBOITA M.S. 2008. Ciclones Extratropicais sobre o Atlântico Sul: Simulação Climática e Experimentos de Sensibilidade. Tese de Doutorado (Doutorado Meteorologia). Instituto de Astronomia, Geofísica e Ciências Atmosféricas, Universidade de São Paulo, São Paulo.

REBOITA M.S., IWABE C.M.N., ROCHA R.P., AMBRIZZI T. 2009. Análise de um ciclone semi-estacionário na costa sul do Brasil 
associado a bloqueio atmosférico. Revista Brasileira de Meteorologia, 24 (4), 407-422.

REBOITA M.S., ROCHA R.P., AMBRIZZI T., SUGAHARA S. 2010. South Atlantic Ocean cyclogenesis climatology simulated by regional climate model (RegCM3). Climate Dynamic, 35, 13311347.

ROCHA R.P., SUGAHARA S., SILVEIRA R.B. 2004. Sea waves generated by extratropical cyclones in the South Atlantic Ocean: hindcast and validation against altimeter data. Weather and Forecasting, 19, 398-410.

RODRÍGUES G., GUEDES SOARES C. 1999. A criterion for the automatic identification of multimodal sea wave spectra. Applied Ocean Research, 21, 329-333.

RODRIGUES M.L., FRANCO D., SUGAHARA S. 2004. Climatologia de frentes frias no litoral de Santa Catarina. Revista Brasileira de Geofísica 22(2), 135-151.

SHORT A.D. 1999. Handbook of Beach and Shoreface Morphodynamics. Book Ed. John Wiley 7 Sons Ltd, England.

SILVA I.R., BITTENCOURT A.C.S.P., DOMINGUEZ J.M.L., MARTIN L. 2001. Principais padrões de dispersão de sedimentos ao longo da costa do descobrimento - Sul do Estado da Bahia. Revista Brasileira de Geociências, 31 (3), 335-340.

SUDERHSA. 2007. Elaboração do Plano Estadual de Recursos Hídricos. Avaliação das disponibilidades hídricas, eventos críticos e monitoramento do uso de recursos hídricos, 1.2, Paraná, Cobrape.

VEIGA F.A. 2005. Processos Morfodinâmicos e sedimentológicos na plataforma interna rasa paranaense. Tese (Doutorado em Geologia Ambiental) - Setor de ciências da terra, Universidade Federal do Paraná, Curitiba.

WANG X.L., SWAIL V.R., ZWIERS F.W. 2005. Climatology and Changes of Extratropical Cyclone Activity: Comparison of ERA40 with NCEP-NCAR Reanalysis for 1958-2001. Journal of Climate, 19, 3145-3166.

WRIGHT T.D., SHORT A.D. 1984. Morfodynamics Variability of Surf Zones and Beach: A Syntheisis. Marine Geology, 56, 93-118. 